\title{
Modeling and Forecasting the Macroeconomic Driver of Time-Varying Coffee Price Volatility in Ethiopia
}

Teshome Hailemeskel Abebe ( $\nabla$ teshome251990@gmail.com )

Department of Economics, Ambo University, P.O.Box, 19, Ambo, Ethiopia

\section{Research}

Keywords: High Frequency data, Time-Varying volatility, Macroeconomic variables, Modeling, Forecasting, Ethiopia

Posted Date: March 11th, 2020

DOI: https://doi.org/10.21203/rs.3.rs-16737/v1

License: (a) (i) This work is licensed under a Creative Commons Attribution 4.0 International License.

Read Full License 


\title{
Modeling and Forecasting the Macroeconomic Driver of Time- Varying Coffee Price Volatility in Ethiopia
}

\author{
Author: TeshomeHailemeskelAbebe \\ E-mail: teshome251990@gmail.com \\ Department of Economics, Ambo University, P.O.Box, 19, Ambo, Ethiopia
}

\begin{abstract}
Recently, modeling and forecasting of high frequency data (such as daily price) volatility using GARCHMIDAS attracts the attention of many researchers. Thus, the objective of this study is to model and forecast the average daily coffee price volatility using GARCH-MIDAS model over the sample period from January 01, 2010 to June 30, 2019. The GARCH-MIDAS component model decomposes the conditional variance into short run component which follows a mean-reverting unit GARCH process and long run component which consider different frequency macroeconomic indicators (in this study GDP, interest rate, trade openness and money supply) via mixed interval data sampling (MIDAS) specification. Unit root test results show the return series are stationary at level, while macroeconomic variables are stationary at first difference except interest rate, which is stationary at level. From the result of estimated GARCH-MIDAS component model, all selected indicators are crucial in explaining the long-term component price volatility. The Conrad \&Schienleregression based result shows the absence of model specification. Moreover, the estimated GARCH-MIDAS component model with money supply as a main driver is used for out-sample forecast. Finally, the DM test statistic used for comparing the forecasting performance of GARCH-MIDAS component model against the standard GARCH model.The result shows that multiplicative GARCH-MIDAS component model provide an explanation for stylized facts that cannot be captured by standard GARCH model.
\end{abstract}

Keywords:High Frequency data; Time-Varying volatility; Macroeconomic variables;Modeling; Forecasting; Ethiopia

\section{Introduction}

Modeling and forecasting volatility of financial returns have become a research area of interest in recent time since volatility modeling is an important tool for policymaking, investment analysis, 
asset pricing and risk management (Andersen, 2005). Specifically, forecasting volatility is a crucial part of decision-making for financial market traders as well aspolicy-makers.

In this regard, Robert Engle in 1982 introduced the first volatility model called Autoregressive conditional heteroscedasticity $(\mathrm{ARCH})$ model. Consequently, different ARCH family modelslike GARCH model (Bollerslev, 1986), EGARCH (Nelson, 1991), and Threshold GARCH(Zakoian, 1994) have been introduced. However, most of the ARCH family models have been developed to capture low frequency data and considered as inappropriate for high frequency data because such data possess a particular characteristic of persistency in unconditional variance (Andersen, 2005).

According to Bollerslev (1998), the standard GARCH family models are accurate for shortterm volatility forecasts. However, long-horizon forecasts for volatility can be important for instance for portfolio allocation and risk management since forecastaccuracy generally varies over time (Engle et al., 2013).

Thus, recently, a number of models for high frequency data were developed by augmenting the traditional ARCH family models to component GARCH models. Engle and Lee (1999) introduced the first additiveGARCHcomponent model, which decomposes volatility into shortterm and long-term volatility component. Subsequently, Engle and Rangel (2008) introduced a multiplicative GARCH component model where the conditional variance is decomposed into transitory and permanent volatility components. The transitory volatility component captures a mean reverting unit GARCH process, while the permanent component captures by the SplineGARCH process that handles theslowly varying deterministic (long-term) componentsince predictability varies over macroeconomic states or conditions.

According to Park et al. (2007) thepermanent component of conditional variance is derived as a result of macroeconomic fundamentals. On the other hand, transitory component of conditional variance is mainly originated from noise traders' transactions or market friction based on the microeconomic effects of financial market structure. Moreover, the transitory component which dies out quickly and is highly volatile, while permanent component which lasts long and is less volatile. However,neither the traditional GARCH models nor the SplineGARCH models independently handle data of having different frequency in model.

Engle et al. (2013) introduced a GARCH-MIDAS component model that combines the nonstationary volatility component of the Spline-GARCH with the Mixed Frequency Data Sampling 
(MIDAS) approach, which was introduced by Ghyselset al. (2007) and allows to directly linking lower frequency macroeconomic variables to high frequency long-term volatility component. In order to simplify the estimation process in GARCH-MIDAS component model, Engleet al. (2013) applied a beta-weighting scheme to link high frequency financial return series to low frequency macroeconomic variables. Even though asymptotic results for the general GARCHMIDAS model are not yet available, Wang and Ghysels (2014) establish the asymptotic normality of the quasi-maximum likelihood estimator for a GARCH-MIDAS model. Moreover, according to Wang \& Ghysels, volatility component models found considerable attention not only because of their ability to capture complex dynamics via a parsimonious parameter structure, but also because they can handle well structural breaks or non-stationarity in financial return volatility.

In this regard, daily coffee price series of Ethiopia have the characteristics of high price volatility and their associated price variation worsen when the macroeconomic conditions of the county become unstable. However, the price series of coffee is available at daily level, while macroeconomic variables cannot be available at higher frequency (like daily) rather they can be measured at lower frequency (annually, quarterly and monthly) since its economy mainly depend on agriculture which is inelastic in supply.

Therefore, this paper explores the time-varying predictive ability provided by macroeconomicvariables, through comparing the out-of-sampleforecasting performance of GARCH-MIDAS models to a standard GARCH model on average daily coffee price of Ethiopia.Specifically, the study aims at (1) to fit an appropriate volatility component model for average daily coffee price volatility, (2) to identify the best determinants of coffee price volatility and (3) to conduct an out-sample forecast on average coffee price volatility using GARCHMIDAS component model.

The remaining part of the paper is organized as follows. Section 2 presents the general methodology of the paper. Section 3 presents the data. Section 4 presents results and discussion. Section 5 presents conclusions and recommendations.

\section{Literature Review}

Volatility is defined as the spread of all likely outcomes of uncertainty or risk of financial assets. Volatility measurement is necessary for the implementation of most economic or financial 
theories that guide investment and market decision. Volatility is also important for assessing the quality of financial markets performance.

Traditionally, the concept of volatility may be confused with rising prices. However, volatility measures how much a price change either with regard to its constant long-term level, or to its trend. In this respect, it is important to note that volatility does not measure the direction of price changes; rather it quantifies the variation of prices around the mean. Data with higher frequencies often result in higher volatility, whereas volatility diminishes when frequencies decrease. Annual data are less volatile than quarterly data and quarterly data are less volatile than monthly data (European Commission, 2009).

According to Poon (2005), the traditional way of volatility measurement is a simple standard deviation or variance. However, such volatility measurement is unconditional and does not capture some characteristics of volatility such as volatility clustering (i.e., large shocks tend to be followed by large shocks and small shocks tend to be followed by small shocks), leverage effect (i.e. volatility reacts differently to a big price increase or a big price drop) and volatility evolves over time in a continuous manner.Therefore, in order to resolve these weaknesses of the traditional measure of volatility, a number of volatility models ( $\mathrm{ARCH}$ family models) were developed subsequently.

However, models in the standard GARCH type assume constant level of unconditional variance even if they let the conditional variances to fluctuate around a changing level. For the GARCH type model, the unconditional variance of the return is constant over time provided that the weak stationarity condition is satisfied. However, this assumption is not consistent with the volatility behavior of the high frequency data (e.g. daily commodity price) if the dynamic behavior of volatility changes in the long run. In other words, these standard GARCH type models are nonstationary since the unconditional variance is time varying which makes the level of the unconditional variance to be affected by macroeconomic variables independent of the short run GARCH dynamics.

The basic idea of decomposing volatility into short-term and long-term components can be traced back to Ding and Granger (1996). Engle and Rangel (2008) considered the long-term component as the setting of the time-varying variance, and proposed the Spline-GARCH model, but both the long-term component and short-term component keep the same frequency in the model setting. Engle et al.(2013) combined the mixed data sampling (MIDAS) technique and the 
volatility model (Ghysels, Santa-Clara and Valkanov, 2006; Ghysels, Sinko and Valkanov, 2007) into the GARCH-MIDAS model to separate the long-term low-frequency components and shortterm high-frequency components, and the new model allowed the use of low-frequency macroeconomic factors to characterize long-term components.

Thus, the GARCH-MIDAS model introduced by Engel et al. (2013) allows decomposing the total price return volatility into short-run and long run volatility component. The long-run volatility component handles the unconditional variance which is time-varying in high frequency data and derived as a result of macroeconomic variables shocks. To link time-varying long-run volatility component (unconditional variance) to low frequency macroeconomics variables, a Mixed Frequency Data Sampling (MIDAS) were adopted.

Subsequently, a number of empirical reviews on GARCH-MIDAS component model were conducted. Few of those empirical reviews, especially commodity markets are as follows.

Nguyen and Walther (2018) investigates the time-varying daily prices volatility patterns of major commodities as well as the potential factors that drive the long-term volatility component using GARCH-MIDAS approach which allows to examine the role of economic and financial variables of different frequencies over period from 1 January 1996 to 31 December 2015. The results show that a GARCH-MIDAS component (short-term and long-term components) model is appropriate in forecasting commodity volatility. They also indicate that the long-term volatility of most commodity futures is significantly driven by the level of global real economic activity, changes in consumer sentiment, industrial production, and economic policy uncertainty. However, the forecasting results are not alike across commodity futures and a single model can fits all commodities.

Ruobing, L. et al. (2019) studiedthe impact of macroeconomic news on Chinese futures, including commodity futures from June 2002 to December 2017 using GARCH-MIDAS model which can decompose the conditional variance into the long-term and short-term component. The result shows that the included macroeconomic variables have a significant impact on the volatility of Chinese futures' return.

Therefore, literature review shows that commodity price volatility is determined by the macroeconomic fundamentals as defined by GARCH-MIDAS component model. Hence, the research a problem of this study is derived from literature review. Therefore, the finding of the study contributes to the existing literature by testing the relation betweenthe fundamental 
macroeconomic variables and price volatility in commodity market. Even though, the study is conducted in Ethiopia coffee market, the result provides information for market participants, and the policymakers to make decision according to the macroeconomic conditions.

\section{Research Methodology}

\subsection{Characteristics of Financial Time Series}

According to Brooks (2008), financial time series have the property of leptokurtic, volatility clustering and leverage effects. Leptokurtic refers to the tendency for financial asset returns to have distributions that exhibit fat tails and peaked at the mean. Volatility clustering indicates that large returns (of either sign) are expected to follow large returns, and small returns (of either sign) to follow small returns that arise as a results of non-normality (non-constant variance of the error terms) in the return series.Leverage effects is a tendency for volatility to rise more following a large price fall than following a price rise of the same magnitude.

Moreover, Harris \&Sollis (2003) stated that financial time series are often available at a higher frequency and such a high-frequency data have the property of long-memory, which is defined as the present information has a persistent impact on future values.

Therefore, the theoretical characteristics of financial time series tell us the need of an advanced model for handling high frequency data (e.g. daily coffee price series of Ethiopia) and its driving forces (macroeconomic variables).

In financial studies, log return series can be analyzed, rather than the actual prices value since the $\log$ returns series are more manageable, have better statistical properties and economic interpretation. In this study, the log return series can be written as:

$$
r_{i, t}=\left(\log p_{i, t}-\log p_{i-1, t}\right)=\log \left(\frac{p_{i, t}}{p_{i-1, t}}\right)
$$

where $p_{i, t}$ is averagecoffee price on day $\mathrm{i}$ of period $\mathrm{t}, r_{i, t}$ is $\log$ return series on day $\mathrm{i}$ of period $\mathrm{t}$.

\subsection{Unit root test}

Empirical work based on time series data assumes that the underlying time series is stationary since non-stationarity leads to spurious (non-sense) results.Nevertheless, most trending variables, like macroeconomic variables are non-stationary by nature. When we have a stationary system, 
effect of a shock will die out gradually. However, when we have a non-stationary system, effect of a shock is permanent. In order to test this effect, the Augmented Dickey Fuller (ADF) and Phillips-Perron (PP) test were used. If the variables have unit root then the series needs to be differenced to achieve stationarity.

\section{The Augmented Dickey Fuller (ADF) Test}

The ADF approach controls higher-order correlation by adding lagged difference terms of the dependent variable to the right-hand side of the regression, which are required to account for possible occurrence of autocorrelation. Consider the AR (p) model given by:

$$
\nabla r_{i, t}=\mu+\alpha r_{i-1, t}+\sum_{k=2}^{p} \emptyset_{k} \nabla r_{i-k, t}+\varepsilon_{i, t}
$$

where $\alpha=-\left(1-\sum_{k=2}^{p} \psi_{i}\right)$ and $\emptyset_{k}=\sum_{j=1}^{p} \psi_{i}$

If the null $\mathrm{H}_{0}: \alpha=0$ is not rejected, apply differencing to make the series stationary.

\section{The Phillips and Perron (PP) Test}

Phillips and Perron (1987) have developed a more comprehensive theory of unit root test. The Phillips-Perron (PP) unit root tests differ from the ADF tests inthe way to deal serial correlation and heteroscedasticity in the errors.

Consider the differencedPPtest equation as an AR (1) processes given by:

$$
\nabla r_{i, t}=\alpha r_{i-1, t}+\varepsilon_{i, t}(3)
$$

DF: $\varepsilon_{i . t} \sim$ iid, while PP: $\varepsilon_{i, t}$ is serially correlated. The null is given by $\mathrm{H}_{0}: \alpha=0$.

Thus Phillips and Perron's test statistic can be viewed as Dickey-Fuller statistic that have been made robust to serial correlation by using the Newey-West (1987) heteroscedasticity and autocorrelation-consistent covariance matrix estimator of the error term, $\varepsilon_{i, t}$ by modifying the test statistics $t_{\alpha=0}$ and $N_{t} \hat{\alpha}$, given that $t_{\alpha=0}=\frac{\widehat{\rho}}{\operatorname{Se}(\widehat{\rho})}$ and $N_{t} \hat{\alpha}=\frac{\widehat{\alpha}}{\operatorname{Se}(\widehat{\alpha})}$.

where $\hat{\rho}$ and $\hat{\alpha}$ are OLS estimate of $\rho$ and $\alpha$, and $S e(\hat{\rho})$ and $S e(\hat{\alpha})$ are standard errors of $\rho$ and $\alpha$, respectively.

The modified statistic is given by:

$$
\begin{aligned}
& Z_{t}=\sqrt{\frac{\hat{\sigma}^{2}}{\hat{\lambda}^{2}}} t_{\widehat{\alpha}=0}-\frac{1}{2}\left(\frac{\hat{\lambda}^{2}-\hat{\sigma}^{2}}{\hat{\lambda}^{2}}\right)\left(\frac{N_{t}(s \cdot e(\hat{\alpha}))}{\hat{\sigma}^{2}}\right) \\
& Z_{\alpha}=N_{t} \hat{\alpha}-\frac{1}{2} \frac{N_{t}^{2}(\operatorname{s.e}(\hat{\alpha}))}{\hat{\sigma}^{2}}\left(\hat{\lambda}^{2}-\hat{\sigma}^{2}\right)
\end{aligned}
$$


where $\hat{\sigma}^{2}$ is consistently estimate from sample varince of $\varepsilon_{i, t}$ and $\hat{\lambda}^{2}$ is estimated consistently from the Newey-West long run variance estimate of $\varepsilon_{i, t} \cdot \hat{\sigma}^{2}=\lim _{N_{t} \rightarrow \infty} N_{t}^{-1} \sum_{i=1}^{N_{t}} E\left(\varepsilon_{i, t}^{2}\right)$ and $\hat{\lambda}^{2}=$ $\lim _{N_{t} \rightarrow \infty} \sum_{i=1}^{N_{t}} E\left(\frac{1}{N_{t}} \sum_{i=1}^{N_{t}} \varepsilon_{i, t}\right)^{2}$. Reject the null hypothesis indicates the series is stationary.

\subsection{The GARCH-MIDAS Component Models Specification}

Engle et al. (2013) developed GARCH-MIDAS component model, which decompose the conditional variance of high frequency returns into a short-term and long-term component. The short-term component captures day-to-day fluctuations in volatility, while the long-term component handles time varying unconditional volatility that can be driven by lowfrequencymacroeconomic variables through MIDAS specification.

The GARCH-MIDAS model introduced by Engle et al. (2013) is a multiplicative twocomponent model for the conditional variance, where the high-frequency (short-term) component is modelled as a standard unit GARCH process, while the low-frequency (longterm)component is determined by macroeconomic variables. The high-frequency (short-term) component can be fluctuating around a slow-moving long-term trend, which is driven by variables evolving at a lower frequency. The Mixed Interval Data Sampling (MIDAS) approach, introduced by Ghyselset al. (2007) deals with the challenges related to using data sampled at different frequencies within the same model, especially it capture the lag structure of the explanatory variables by a known function which depends on only a few parameters.

The mean equation of the return $\left(r_{i, t}\right)$ on day $\mathrm{i}$, period $\mathrm{t}$ under GARCH-MIDAS model can be written as:

$$
r_{i, t}=\mu+\varepsilon_{i, t}=\mu+Z_{i, t} \sqrt{\tau_{t} \cdot h_{i, t}}, \quad \forall_{i}=1, \ldots \ldots N_{t}(5)
$$

wherer $_{i, t}$ is the return on day $\mathrm{i}\left(\mathrm{i}=1, \ldots, N_{t}\right)$ in period $t(t=1, \ldots, \mathrm{T})$. The period $t$ may be monthly, quarterly or annually depend on the frequency of macroeconomic variables. The expected return is assumed to be constant i.e. $E\left(r_{i, t} \mid \psi_{i-1, t}\right)=\mu$ for all $\mathrm{i}$ and $\mathrm{t}$, where $\psi_{i-1, t}$ contains the information set up to $(i-1)^{\text {th }}$ day of periodt.

The innovation sequence, $\varepsilon_{i, t}$ in the given mean equation is $\varepsilon_{i, t} \mid \psi_{i-1, t} \sim N\left(0, \sigma_{i, t}^{2}\right)$. Furthermore, each innovation sequence, $\varepsilon_{i, t}$ in high frequency data is decomposed as $\varepsilon_{i, t}=\sigma_{i, t} z_{i, t}$, where 
$\sigma_{i, t}>0, z_{i, t}$ and $\sigma_{i, t}$ are independent by assumptions. $Z_{i, t}$ is a shock with a standardized normal distribution as defined $Z_{i, t} \mid \psi_{i-1, t} \sim i . i . d .(0,1)$. Within the GARCH-MIDAS framework, the conditional variance, $\sigma_{i, t}^{2}$, is given by the product of two components. One varying by each day $i$, namely $h_{i, t}$ as a transitory (short-run) component and the other by each period $\mathrm{t}$, namely $\tau_{t}$, as permanent (long-run) component as given by: $\sigma_{\mathrm{i}, \mathrm{t}}^{2}=\mathrm{h}_{\mathrm{i}, \mathrm{t}} \cdot \tau_{\mathrm{t}}$.

\section{Ttransitory volatility component specification}

According to Engle et al. (2013), the volatility dynamics of the short-term(transitory)component, $h_{t, i}$ follows a mean reversion GARCH $(1,1)$ process:

$$
h_{i, t}=(1-\alpha-\beta)+\alpha\left(\frac{\varepsilon_{i-1, t}^{2}}{\tau_{t}}\right)+\beta_{j} h_{i-1, t}
$$

where $\alpha$ represents ARCH term, $\beta$ is the GARCH term, $\omega_{o}=(1-\alpha-\beta)$ is the constant term. Equation (6) is assumed to satisfy conditions for non-negativity of the variance, i.e. $\alpha \geq 0, \beta \geq 0$ and weak stationary of the conditional variance i.e. $\alpha+\beta<1$ should be satisfied.

\section{Permanent Component (MIDAS) specification}

Thepermanent(long-run) component $\tau_{t}$ is assumed to respond to macroeconomic conditions over a relatively long period. Thus, in the spirit of MIDAS regression and filtering, the $\tau_{t}$ component is assumed a smoothed measure of past values of macroeconomic variables.

Engle et al. (2013) stated that expectation of short-term component, $\mathrm{E}\left(h_{i, t} \mid \psi_{i-1, t}\right)$ converges to unity, i.e. to the unconditional variance of $\mathrm{h}_{\mathrm{i}, \mathrm{f}}$ for large $\mathrm{i}$. Moreover,the standardized residual, $Z_{i, t} \mid \psi_{i-1, t} \sim N(0,1)$. Together with Engle et al. (2013) assumptions of $\mathrm{E}\left(h_{i, t} \mid \psi_{i-1, t}\right)=1$, the long-term volatility component, $\tau_{t}$ could be predetermined with respect to its information set. This can be derived as follows:

$$
\begin{aligned}
& \mathrm{E}\left[\left(\mathrm{r}_{\mathrm{i}, \mathrm{t}}-\mu\right)^{2} \mid \psi_{i-1, t}\right]= \mathrm{E}\left\{\mathrm{E}\left(\varepsilon_{\mathrm{i}, \mathrm{t}}{ }^{2} \mid \psi_{i-1, t}\right)\right\} \\
&= \mathrm{E}\left\{\mathrm{E}\left(\mathrm{Z}_{\mathrm{i}, \mathrm{t}}{ }^{2} \mid \psi_{i-1, t}\right) \mathrm{E}\left(\sigma_{\mathrm{i}, \mathrm{t}}^{2} \mid \psi_{i-1, t}\right)\right\}, \text { since } \mathrm{z}_{\mathrm{i}, \mathrm{t}} \& \sigma_{\mathrm{i}, \mathrm{t}} \text { are independent } \\
&= \mathrm{E}\left(\mathrm{z}_{\mathrm{i}, \mathrm{t}}{ }^{2} \tau_{\mathrm{t}} \mathrm{h}_{\mathrm{i}, \mathrm{t}} \mid \psi_{i-1, t}\right), \text { given }{\sigma_{\mathrm{i}} \mathrm{t}}^{2}=\tau_{\mathrm{t}} \mathrm{h}_{\mathrm{i}, \mathrm{t}} \\
&= \tau_{\mathrm{t}} \mathrm{E}\left(\mathrm{h}_{\mathrm{i}, \mathrm{t}} \mid \psi_{i-1, t}\right), \text { given, } \mathrm{z}_{\mathrm{i}, \mathrm{t}} / \psi_{i-1, t} \sim N(0,1) \\
&= \tau_{\mathrm{t}}, \text { by Engle assumption } \mathrm{E}\left(\mathrm{h}_{\mathrm{i}, \mathrm{t}} \mid \psi_{i-1, t}\right)=1 \\
& \therefore \mathrm{E}\left[\left(\mathrm{r}_{\mathrm{i}, \mathrm{t}}-\mu\right)^{2} \mid \psi_{i-1, t}\right]=\tau_{\mathrm{t}}
\end{aligned}
$$


Building an optimal model representation with macroeconomic variables requires the selection of the time span $\mathrm{t}$ and the MIDAS lag $(\mathrm{k})$ which is used in the MIDAS polynomial specification of the long-term component. Therefore, the effect of macroeconomic variables on the long-term variance component as defined by Engle et al.(2013) is specified as:

$$
\log \tau_{t}=m+\theta \sum_{k=1}^{k} \varphi_{k}\left(\omega_{1}, \omega_{2}\right) X_{t-k}(7)
$$

where $\varphi_{k}\left(\omega_{1}, \omega_{2}\right)$ is a weighting scheme, $m$ is constant term, $X_{t-k}$ is a vector of macroeconomic variables, $\mathrm{K}$ is the number of lags for exogenous variable included, and $\theta$ is the sign effect of each of the macroeconomic variables on the long term volatility component.Engleet al. (2013) explained thatthe Beta lag structure is more flexible to accommodate various lag structures. The logarithmic specification ensures non-negativity of the long-term volatility component $\left(\tau_{t}\right)$ even when the explanatory variable takes negative values. If the variable does not affect stock market volatility (i.e., $\theta=0$ ), all volatility is captured by the short-term component and the model collapses to the GARCH model with $\tau_{t}=m$, i.e., unconditional volatility is constant.

The Beta-weighting scheme $\varphi_{k}\left(\omega_{1} \omega_{2}\right)$ is introduced to MIDAS by Ghyselset al. (2007) is given by:

$$
\varphi_{k}\left(\omega_{1} \omega_{2}\right)=\left(1-\frac{k}{K}\right)^{\omega_{1}-1}\left(\frac{k}{K}\right)^{\omega_{2}-1}
$$

where $\sum_{k=1}^{K} \varphi_{k}\left(\omega_{1} \omega_{2}\right)=1$ and $\varphi_{k} \geq 0$ for $k=1, \ldots, K$. The weight parameters, $\omega_{1}$ and $\omega_{2}$ govern the shape of the weighting scheme.

\subsection{Estimation of the GARCH-MIDAS component model}

To estimate volatility model, maximum likelihood can be employed. Moreover, volatility model specification also requires an assumption about the conditional distribution of the error term such as normal distribution, t-distribution, and Generalized Error Distribution (GED). However, in most financial data, normality assumption is questionable, so the usual standard error estimates will be inappropriate, and a different variance-covariance matrix estimator that is robust to non-normality due to Bollerslev and Wooldridge (1992) should be used. This maximum likelihood with Bollerslev-Wooldridge standard errors is known as quasi-maximum likelihood (QML). Consistency and asymptotic normality of the QML estimator for GARCH-MIDASmodel with realized volatility was established in Wang and Ghysels (2014. 


\subsection{Model Diagnostic Tests}

\section{Model Selection Test}

In the estimation process of GARCH-MIDAS model, identification of the number of time lag and determination of the most drivers of price return volatility, the Akaike information criterion (AIC) can be used as defined by:

$$
A I C=-2 \ln (L)+2 K
$$

where $L$ is the log likelihood function, $K$ is the number of estimated parameters. The model that has a minim value of information criterion will be chosen

\section{Model Misspecification Test}

In order to check the legitimacy of a time-varying long-term component, a Conrad \&Schienle (2018) regression-based misspecification test was used. Under this test, the null hypothesis stated a constant long-term component (simple GARCH).

Conrad \&Schienle (2018) linear regression model based test is specified as follow:

$$
\log R V_{t}=\alpha_{0}+\alpha_{1} X_{t-1}+\rho \log R V_{t-1}+\varepsilon_{t}
$$

where $R V_{t}$ is the aggregated (based on the frequency of macroeconomic variables) realized variance based on the daily, standardized residuals from the simple GARCH model, $X_{t-k}$ is the lagged different frequency (monthly, quarterly and annually) macroeconomic variable. The basic idea of the test is to check whether the realized variance should not be predictable. If $\alpha_{1}$ is statistically different from zero, we can reject the null hypothesis of a constant long-term component, indicating that macroeconomic variables are able to predict the realized variance. Hence, a time-varying long-term component is appropriate and the GARCH-MIDAS model is a valid model for coffee price volatility.

\section{Goodness of fit}

Engle et al. (2013) use a variance ratio to determine the effect of explanatory value on the longterm volatility. Thus, the variance ratio (VR) test is defined as:

$$
V R=\frac{\operatorname{var}\left(\log \left(\tau_{t}\right)\right)}{\operatorname{var}\left(\log \left(h_{i t} \tau_{t}\right)\right)}=\frac{\operatorname{var}\left(\log \tau_{t}\right)}{\operatorname{var}\left(\log \left(\sigma_{i t}\right)\right)}
$$

where variance ratio $(V R)$ is the measure describes the proportion of variance of the logarithmic long-term volatility and the variance of the logarithmic conditional volatility. The variance ratio 
can be interpreted as a measure of fit in the sense that the higher the variance ratio is, the larger is the share of the total expected volatility that can be explained by the variation in the long-term component.

\subsection{Forecasting using GARCH-MIDAS component model}

After the model was estimated and a misspecification tests were conducted, the next step is to forecast the price return volatility using the identified GARCH-MIDAS model with macroeconomic variables. The out-of-sample forecasting period was from January 2019 to June 2019. For the GARCH model the forecastfor day $\mathrm{i}$ is formed as:

$$
E\left(h_{i, t} \mid N_{t-1}\right)=1+(\alpha+\beta)^{i-1}\left(h_{1, t}-1\right)
$$

where $N_{t}$ is the number of trading days in period $\mathrm{t}$, and $N_{t-1}$ denotes the information set in period $t-l, \mathrm{t}$ is time of the forecast origin and $l$ is the lead time forecast.

As we remember, we estimate the parameters from the in-sample period up to T. Therefore, thelstep-head forecast of $\hat{\sigma}_{i, t+l}^{2}$ is given by:

$$
E\left[h_{i, t+l} \tau_{t} \mid N_{t-1,}\right]=\hat{\sigma}_{i, t+l}^{2}=\tau_{t}\left[(1-\alpha-\beta)+\sum_{i=0}^{l}(\alpha+\beta)^{i}+(\alpha+\beta)^{l} h_{i, t}\right]
$$

\subsection{Evaluation of Forecasting Accuracy}

In order to check whether the forecasted value is valid or not, we need to apply a test that evaluate the forecasted value in reference to the actual vale. For evaluating the forecasted value, the Modified Diebold and Mariano Test wasemployed.

\section{Modified Diebold and Mariano Tests}

Diebold and Mariano (1995) developed a test to compare whether two different models have equal forecasting accuracy. Thus, the DM test is used to compare the predictive ability of GARCH-MIDAS model with macroeconomic variables against the standard GARCH model.

Let $\varepsilon_{h t}$ denotes the forecast error from GARCH model with constant long-term component and $\varepsilon_{m t}$ denotes the forecast error from GARCH-MIDAS model with macroeconomic variables. From the two forecast error we can calculate the loss difference $\left(d_{t}=\varepsilon_{h t}-\varepsilon_{m t}\right)$ with mean, $\bar{d}=\frac{1}{N} \sum_{t=1}^{N} d_{t}$.

Then the null hypothesis is given by $H_{0}: \bar{d}=0$ : 


$$
\operatorname{Var}(\bar{d})=\frac{1}{N}\left[\gamma_{0}+2 \sum_{k=1}^{k-1} \gamma_{k}\right]
$$

where $\gamma_{k}$ is the $k^{t h}$ autocovariance of $d_{t}$ given by $\hat{\gamma}_{k}=\frac{1}{N} \sum_{t=k+1}^{N}\left(d_{t}-\bar{d}\right)\left(d_{t-k}-\bar{d}\right)$

The DM test statistic is given by:

$$
D M=\frac{\bar{d}}{\sqrt{\operatorname{var}(\bar{d})}} \sim N(0,1)
$$

Reject the null for all $|D M|>1.96$

\section{Data, ResultsandDiscussions}

\subsection{Data Sources}

Daily data on average price of coffeecover from the period January 1, 2010 to June 30, 2019 were obtained from Ethiopian commodity exchange (ECX) market, while data on macroeconomic variables, such as GDP, interest rate, trade openness and money supplywere obtained from NBE andMoFED. The variables of interest in this study are average daily coffee price, which is to be used as dependent variable, whileGDP, trade openness, money supply (M2) and interest rate are exogenous variables.

\subsection{Summary Statistics Results}

The following graph displays daily average coffee price and return series in the full sample period over January 01, 2010 to June 30, 2019.

Figure 1: Average daily coffee price series from January 1, 2010 to June 30, 2019

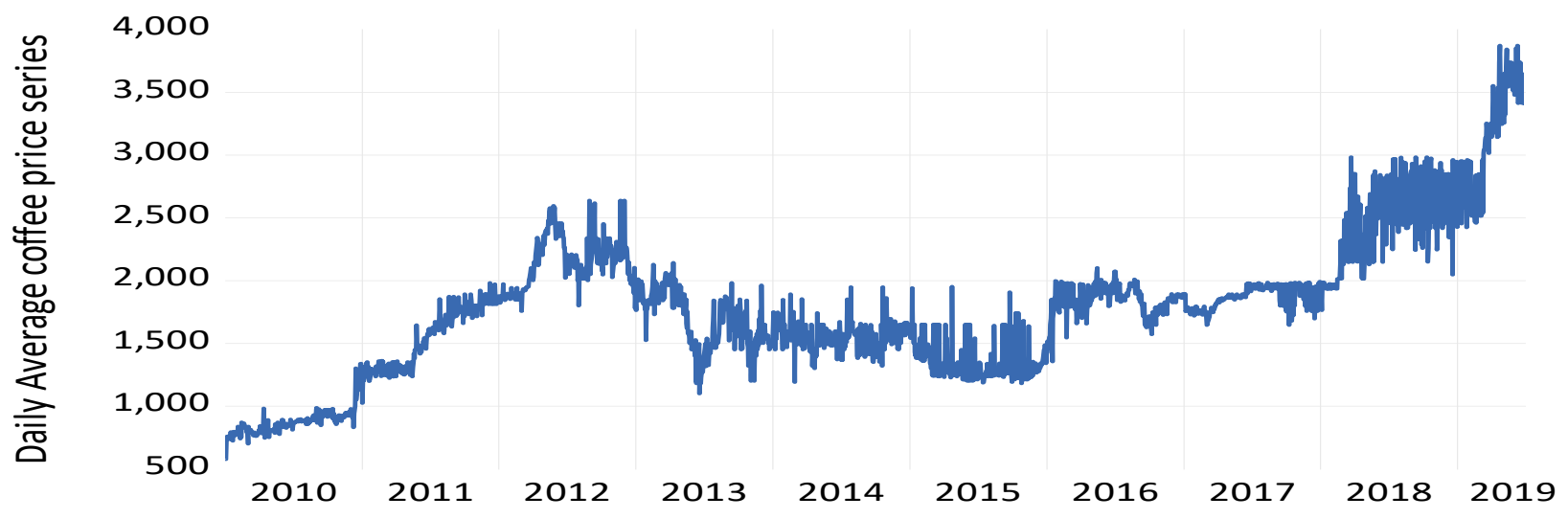

Source: Author's computations 
From the figure, it can be observed that an average daily coffee price have a fluctuating behavior over all the time period. Specifically, the series rise until the end of 2012 and then decline until 2017. However, after 2017 there is a continue rise in the series.

The plot on Figure 2 shows an average daily price return series. The series seems to satisfy the stylized fact of financial time series that is the existence ofvolatility clustering (highvolatility events tend to clusterin time) in the series.

Figure 2: Average Daily coffee Return series from January 01, 2010 to June 30, 2019

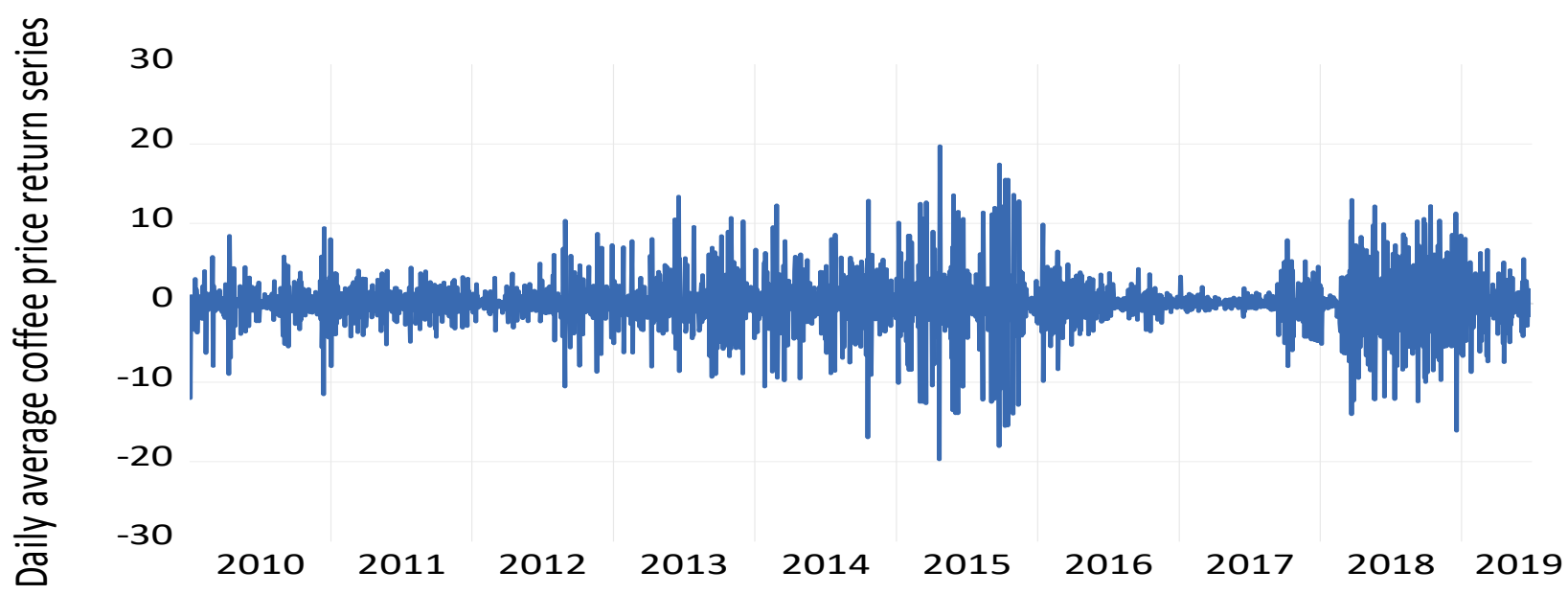

Source: Author's computations

Table 1 presents the coefficients of skewness and kurtosis of average daily coffee price and return series together with the results of the Jarque-Bera tests. From Table the return series exhibit excess kurtosis that is one of the stylized facts of high frequency financial time series. The Jarque-Bera tests reject the null hypothesis of normality indicating other distribution.

Table 1: Summary statistics for average daily coffee price and return series

\begin{tabular}{lcc}
\hline Statistics & Average price series & Average logreturn series \\
\hline Skewness & -0.0867 & -0.3979 \\
Kurtosis & 2.4186 & 13.0301 \\
Jarque-Bera & 27.6351 & 7601.2070 \\
P-value & 0.0001 & 0.0000 \\
\hline
\end{tabular}

Author's computations 
Table 2:Summary results for economic variables

\begin{tabular}{|l|l|l|l|l|}
\hline Statistics & GDP & Interest rate & Money supply & Trade Openness \\
\hline Mean & 266842.5 & -3.22671 & 44048.3 & 136.766 \\
\hline Median & 180911.0 & -0.95630 & 43079.7 & 75.5416 \\
\hline Max & 810187.0 & 19.0787 & 53099.3 & 522.250 \\
\hline Min & 104248.0 & -51.2413 & 36717.1 & 16.0544 \\
\hline Std. Dev & 195735.4 & 14.5039 & 4850.53 & 156.043 \\
\hline
\end{tabular}

\section{Author's computations}

\subsection{Unit Root Test Results}

Before estimating the models, the first step is to check the stationarity of the series. In this study, the ADF and PP unit root test were used. Table 3 shows that the ADF and PP test of daily $\log$ return series for coffee is stationary at $1 \%$ level of significance indicating the return series are stationary at level than the price series.

Table 3: Unit root test results at level for daily coffee price log-return series

\begin{tabular}{|l|l|l|l|l|l|}
\hline $\begin{array}{l}\text { Averagedaily } \\
\text { coffee price } \\
\text { return series }\end{array}$ & Include test equation & \multicolumn{2}{|l|}{ ADF Test } & \multicolumn{2}{l|}{ PP Test } \\
\cline { 3 - 6 } & & Test statistic & P-value & Test statistic & P-value \\
\cline { 2 - 6 } & With intercept & -26.483 & 0.0000 & -88.836 & 0.0001 \\
\cline { 2 - 6 } & With intercept and trend & -26.507 & 0.0000 & -89.708 & 0.0001 \\
\hline
\end{tabular}

Author's computations: MacKinnon (1996) one-sided p-values

From Table 4 we observed that ADF and PP unit root test of interest rate is stationary at level, while other explanatory variables are non-stationary at level. However, all non-stationary variables at level become stationary after first differences as indicated by the p-value. Therefore, we should to use the first difference of those explanatory variables in the estimation process. 
Table 4: Unit root test results of explanatory variables at level and first difference

\begin{tabular}{llcccccccc}
\hline & & \multicolumn{4}{c}{ At level } & \multicolumn{3}{c}{ First difference } \\
\cline { 3 - 10 } Series & \multirow{2}{*}{ Test equation } & \multicolumn{2}{c}{ ADF Test } & \multicolumn{2}{c}{ PP Test } & ADF Test & \multicolumn{2}{c}{ PP Test } \\
\cline { 3 - 10 } & & $\begin{array}{c}\text { Test } \\
\text { statistic }\end{array}$ & $\begin{array}{c}\text { P- } \\
\text { value }\end{array}$ & $\begin{array}{c}\text { Test } \\
\text { statistic }\end{array}$ & $\begin{array}{c}\text { P- } \\
\text { value }\end{array}$ & $\begin{array}{c}\text { Test } \\
\text { statistic }\end{array}$ & $\begin{array}{c}\text { P- } \\
\text { value }\end{array}$ & $\begin{array}{c}\text { Test } \\
\text { statistic }\end{array}$ & $\begin{array}{c}\text { P- } \\
\text { value }\end{array}$ \\
\hline $\begin{array}{l}\text { Interest } \\
\text { rate }\end{array}$ & With intercept & -5.048 & 0.002 & -5.088 & 0.002 & & & & \\
\hline $\begin{array}{l}\text { Money } \\
\text { supply }\end{array}$ & With intercept and trend & -5.462 & 0.001 & -5.449 & 0.004 & & & & \\
\hline $\begin{array}{l}\text { Trade } \\
\text { openness }\end{array}$ & With intercept & 0.489 & 0.983 & 0.074 & 0.958 & 3.234 & 0.001 & 6.054 & 0.000 \\
& With intercept & 2.465 & 1.000 & 2.503 & 1.000 & -1.299 & 0.618 & -5.243 & 0.001 \\
\hline GDP & With intercept and trend & -0.362 & 0.985 & -0.307 & 0.984 & -6.603 & 0.000 & -6.612 & 0.000 \\
\hline
\end{tabular}

Author's computations: MacKinnon (1996) one-sided p-values

\subsection{Estimation Results of GARCH-MIDAS Model}

Table 5 gives the estimated GARCH-MIDAS model for daily average coffee price return with different frequency macroeconomic variables using beta-weighting scheme.For each series, the first differences of each economic variable were used except interest rate, which is used at level. To estimate the model, the QMLE method with generalized error distribution (GED) distribution was used. Estimation of GARCH-MIDAS model is computationally complex and the inclusion of several macroeconomic variables at a time results convergence problems. Thus, the researcher uses one variable at a time in the MIDAS equation. The numbers in the first row is the coefficient for each independent variable, while the second row is the corresponding P-value.

Under GARCH-MIDAS component model the most interesting parameters are the slope parameters $\left(\theta^{\prime} s\right)$ and thus the interpretation depend on this parameter. Thus, as defined by Engle et al. (2013), the magnitude effect of macroeconomic variables on the long-term volatility component under MIDAS specification is calculated as $\exp \left[\theta \varphi_{1}(\omega)\right]-1$, the generalized betaweighting function evaluated at $\omega_{2}$ and $\omega_{1}=1$ using the optimum number of lags (K) determined via information criteria and $\theta$ is the direction and magnitude effect of each of the 
macroeconomic variables on the long-term volatility component $(\tau)$ under MIDAS specification.

Table 5: Estimates of GARCH-MIDAS component model

\begin{tabular}{|l|l|l|l|l|l|l|l|l|}
\hline Variables & $\mu$ & $\alpha$ & $\beta$ & $M$ & $\omega_{2}$ & $\theta$ & AIC & VR \\
\hline \multirow{2}{*}{ M2 } & 0.021 & 0.0002 & 0.7848 & 0.0025 & 3.7421 & 0.5455 & -16.254 & 0.8342 \\
\cline { 2 - 8 } & 0.0060 & 0.0074 & 0.0006 & 0.0005 & 0.00030 & 0.002 & & \\
\hline $\begin{array}{l}\text { Trade } \\
\text { Openness }\end{array}$ & -0.0005 & 0.0245 & 0.6547 & -0.0001 & 2.1662 & 0.3421 & -12.787 & 0.6819 \\
\cline { 2 - 8 } & 0.1722 & 0.0001 & 0.0007 & 0.1373 & 0.0035 & 0.0006 & & \\
\hline \multirow{2}{*}{ GDP } & -0.0005 & 0.0080 & 0.8021 & -0.0005 & 1.6595 & -0.4122 & -12.480 & 0.5642 \\
\cline { 2 - 8 } & 0.1213 & 0.0001 & 0.0438 & 0.0003 & 0.0001 & 0.0007 & & \\
\hline Interest rate & 0.0230 & 0.1116 & 0.6950 & 0.0030 & 2.5377 & -0.0461 & -11.819 & 0.7123 \\
\cline { 2 - 7 } & 0.0819 & 0.0254 & 0.0002 & 0.0152 & 0.0004 & 0.0414 & & \\
\hline
\end{tabular}

Author's computations: The numbers in the second row of each variable are p-valueindicate significance at the 1\%, 5\%, and 10\% level. Where AIC is the Akaike information criteria.The variance ratio $(V R)$ represents the proportion of long-term variance to total variance. The model is estimated with a restricted $\left(\omega_{1}=1\right)$.

\section{Money Supply (M2)}

From the Table 5, 12 lags in the MIDAS filter of money supply specification was identified based on AIC. It is clear that the mean of the returns, $\mu$ is insignificant (not significantly differ from zero), meaning that the average mean doesn't explain the returns volatile, whilem is statistically significant at $1 \%$ level of significance. The weight scheme $\omega_{2}$ is statistically significant at $1 \%$ level of significance, which indicates it gives highest weight for most recent observation or lags. Moreover, $\alpha$ and $\beta$ are strongly significant at $1 \%$ level of significance indicatingthe existence of conditional heteroscedasticity and autocorrelation.Compared with the standard GARCH model, the sum of $\alpha$ and $\beta$ become lower when adding independent variables indicatingthat the short-term volatility component is mean reverting to the long-term trend. Thus, adding the independent variables helped in making conditional volatilitymore reactive to market shocks, and improved the significance of the estimationparameters. The impact of money supply defined by the slope parameter $\theta$ on long-term component is positive and statistically significant 
at $1 \%$ level of significance, indicating that an expansionary monetary policy results increase price volatility since excess money supply leads to an increase transaction demand for money which increase demands to commodity. The coefficient of 12 lag money supply on long-term component is 0.5455 . Putting $\omega_{1}=1$, the weighting function $\varphi_{1}(\omega)=0.289$, then the magnitude effect of money supply on the long-term volatility component defined byexp $^{\left[\theta \varphi_{1}(\omega)\right]}-1=0.1708=17.08 \%$. Thus, as a $1 \%$ increases in current month money supply results a $17 \%$ increase in long-term coffee price volatility. The positive sign of $\theta$ estimates in money supply have the expected sign. The coefficient is positive, indicating that an increase in money supply implies negative shocks for the economy in terms of price fluctuation.

\section{Trade openness}

Trade openness specification of 6 MIDAS lag for long-term price return series was identified based on the minimum AIC. The magnitude effect of trade openness on the long-term volatility component of price return is calculated as $\exp \left[\theta \varphi_{1}(\omega)\right]-1=0.1290=12.90 \%$. Therefore, a $1 \%$ increase in this quarter trade openness results in $12.90 \%$ increase in long-term price return volatility. The $\theta$ estimates in trade openness have the expected sign positive, which indicates an increase in the trade openness implies a negative shock for the economy in terms of price volatility. Economically, the result is interpreted as an economy that is highly integrated into the world market creates uncertainty in the domestic price since any change the economic condition of the external world in an open economy leads to a change in the domestic price of coffee.

\section{Gross Domestic Product (GDP)}

The slope parameter estimates of GDP indicated by $\theta$ on the long-term component of MIDAS specification is negative and significant at $1 \%$ level of significance, meaning that an increase overall level of economic activities leads to lower the levels of coffee price volatility. In other words, growing economy results stabilization effect on price volatility in the economy. The magnitude effect of GDP on the long-term component is given by $\exp \left[\theta \varphi_{1}(\omega)\right]-1=-0.1674=-$ $16.74 \%$. Hence, a $1 \%$ increase in gross domestic product in this quarter would decreases longterm price volatility by $16.74 \%$. Therefore, an increase in GDP implies a positive shock for the economy (reduce price volatility or uncertainty) in the long run.

\section{Interest rate (Real Interest Rate)}


The real interest rate effect on long-term price volatility under MIDAS specification is negative and statistically significant at $5 \%$ level of significance for coffee price return volatility. Economically lower interest rate results higher price volatility while higher interest rates results lower price volatility. This might be due to that low interest rate promote price volatility via low interest rates tend to reduce the opportunity cost of carrying inventories and increasing the demand for coffee which results an increase in price volatility. The magnitude effect of real interest rate on the long-term volatility component is $-0.3371 \%=-3.37 \%$. Thus, a $1 \%$ increase in real interest rate results $3.37 \%$ declines in price volatility in the long-run. This supports the hypothesis that a decline in interest rate reduces the opportunity cost to hold inventories, hence making the market thinner and reducing the ability to cope with shocks.

From Table 5, the long-term component of the GARCH-MIDAS explained by the fluctuation of the variation in the explanatory variable in a range between $56 \%$ and $83 \%$ as indicated by variance ratio (VR) test. In order to decide which model is the best and which independent variables best fits the sample data we take into consideration the Akaike InformationCriterion (AIC). Thus, the GARCH-MIDAS model, which incorporates the monthly money supply (M2) yields the best goodness-of-fit of the model (based on minimum AIC). Hence, money supply is considered as the main deriver of average daily coffee price return volatility in the long run.

Figure 3: In-sample estimate of average coffee price return volatility

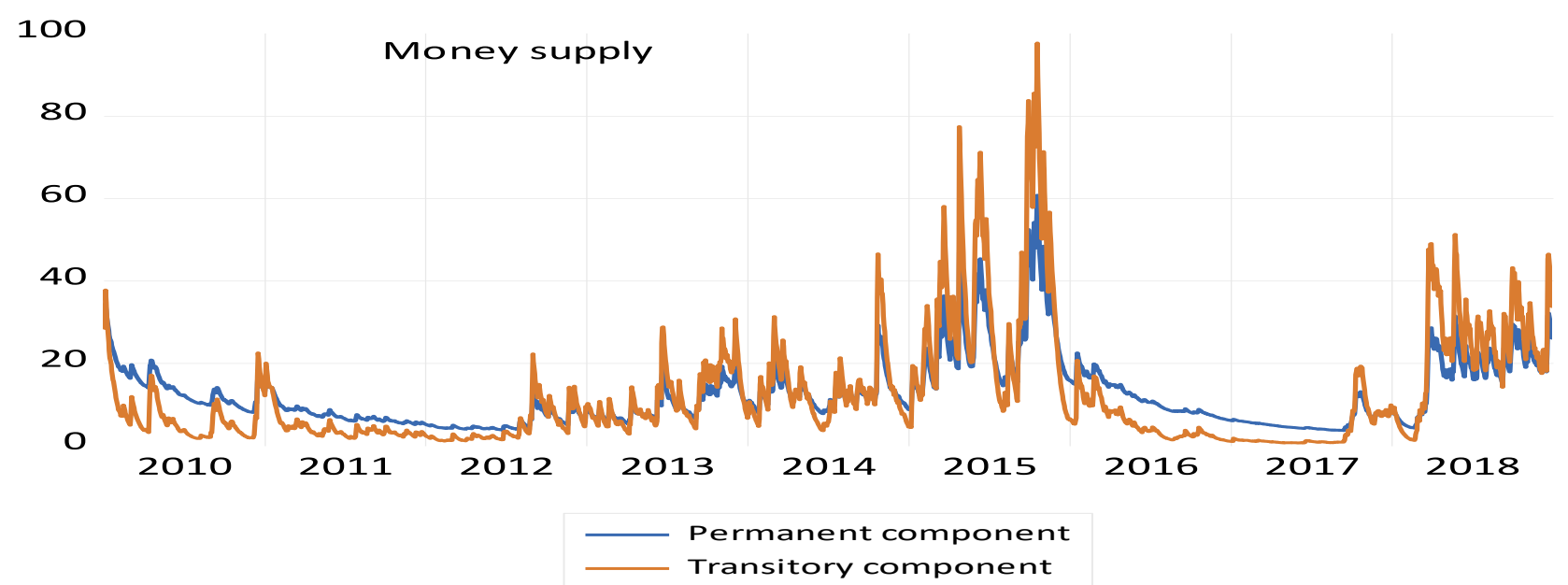

The Figure 3 shows the daily long-term (blue line) and short-term (red line) volatility components as estimated by the GARCH-MIDAS models with money supply as explanatory variables. 


\subsection{Misspecification test Results}

Table 6 shows the the estimated results of regression based misspecification test proposed by Conrad \& Schienle (2018). The values presented are p-values for the coefficient of each explanatory variable on log realized volatility of average daily coffee price return series. Thus, the result shows the existence of long-term volatility component in the average daily coffee price return volatility series. Since a time-varying long-term component model seems reasonable, we confirm the validity of GARCH-MIDAS component model for the in-sample data to identify the main drivers of shocks in the long-term volatility component.

Table 6: Misspecification Test results

\begin{tabular}{|l|l|}
\hline Variables & Log realized volatility of average daily coffee price return series \\
\hline Money supply (M2) & 0.0000 \\
\hline Trade Openness & 0.0017 \\
\hline GDP & 0.0035 \\
\hline Interest rate & 0.0231 \\
\hline
\end{tabular}

Author's computations

\subsection{Out sample Forecasting using GARCH-MIDAS Component model}

In this study, the GARCH-MIDAS specifications with macroeconomic variables are used for forecasting commodity price volatility, which is helpful for managers, traders, consumers and other stakeholders. Thus, after fitted the in sample data, the selected model will be used for outsample forecasting. In this case, the out sample data was used from January 1, 2019 to June 3, 2019. Moreover, to forecast the future value of the series, money supply is used as the main deriver (based on minimum AIC; see Table 5) of average daily coffee price volatility in GARCH-MIDAS model. From the result in Figure 4, the forecast seems stable except on April (the fourth month) in which there is a rise in the price of the series might be due to domestic market supply conditions. 
Figure 4: Out-sample forecasting of average coffee price return volatility

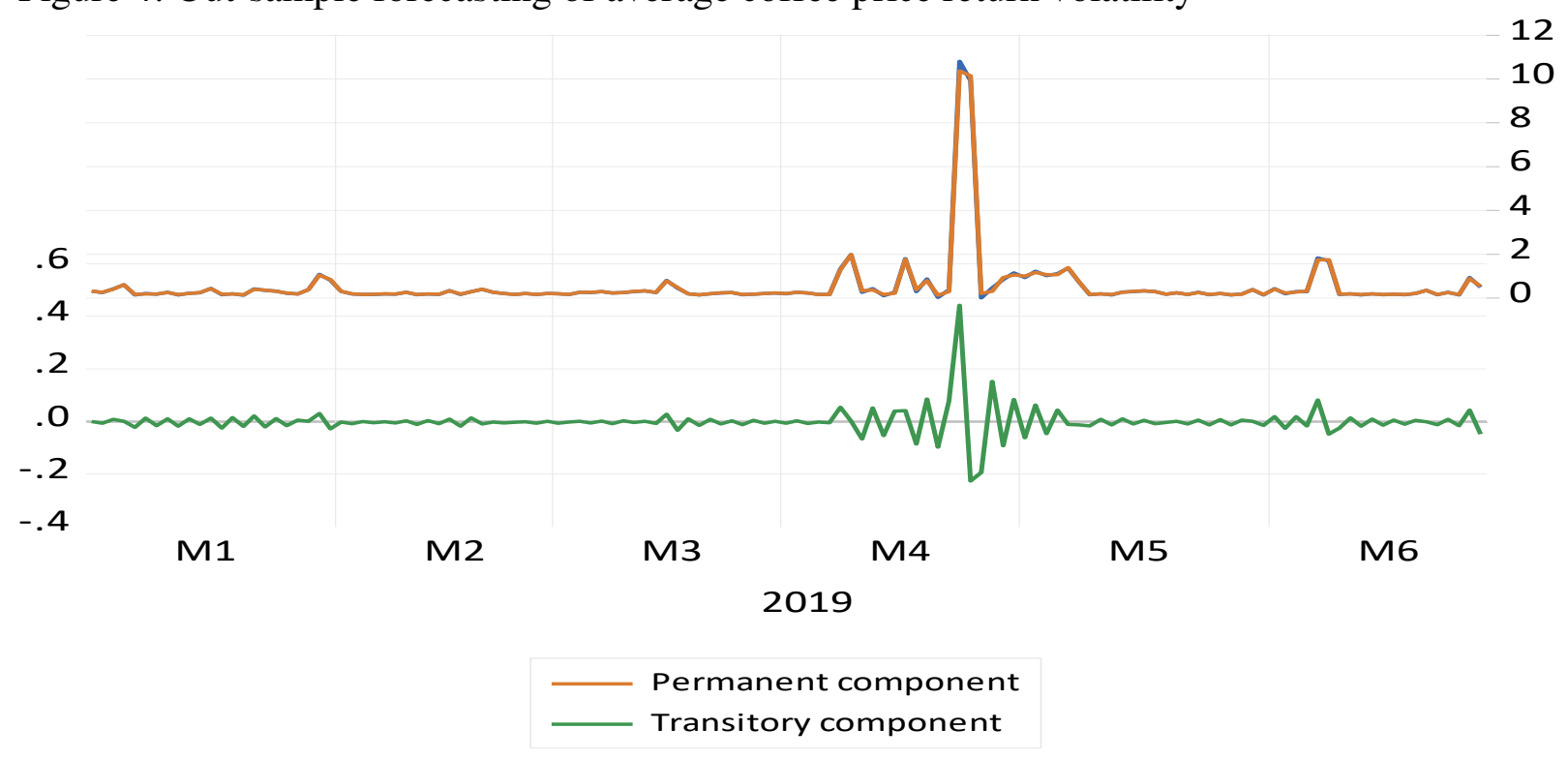

\subsection{Evaluation of Forecasting Accuracy}

\section{Modified Diebold and Mariano Tests Results}

Table7shows the results of the estimated DM-test for the out-of-sample performance of the GARCH-MIDAS model against standard GARCH mode, which is a benchmark model in predicting daily price volatility. From the table, the p-value is statistically significant at $1 \%$ level of significance indicating rejection of the null hypothesis. Thus, we reject the null of equal forecasting accuracy between identified GARCH model and GARCH-MIDAS component model. Therefore, we conclude that the GARCH-MIDAS component model outperforming than standard GRACH model in the out sample forecasts of average daily coffee price volatility of a given data.

Table 7: Modified Diebold and Mariano Tests results

\begin{tabular}{|l|l|l|l|}
\hline Series & Model & Test statistic & P-value \\
\hline Daily coffee price return & GARCH(1,1) Vs GARCH-MIDAS-X & & 0.0003 \\
& & -6.7543 & \\
\hline
\end{tabular}

Author's computations 


\section{Conclusions and Recommendations}

\subsection{Conclusions}

The main motives of this article is to forecast the future value of average coffee price series using a versatile class of volatilitycomponent model combining the insights of spline-GARCH and MIDAS filters called GARCH-MIDAS model. This component model allowed decomposing volatility into short-run and long-run component sources of volatility and linkingthem directly to macroeconomic variables (GDP, interest rate, trade openness and money supply). In the study, the researcher conducted in-sample estimation, identification ofthe main driver of long-term coffee price volatility in the in-sample estimations, and out-of-sample volatility forecasting.

The ADF and PP unit root test shows that the return series is stationary and almost all economic variables are stationary at firs difference except interest rate, which is stationary at level. The estimated result of GARCH-MIDAS component model show that all explanatory variables are statistically significant which indicates that changing values of these indicators anticipate changing future values of price volatility. Thus, the change in long-term component of price volatility is related to macroeconomic conditions. The better the macroeconomic situation in the country, the lower the volatility of the price in the market and hence its macroeconomic environment determines the stability of coffee prices. Therefore, inclusion of macroeconomic variable is helpful in forecasting the long-run price volatility. The model diagnostic result shows the existence of time varying unconditional variance (long-term component) in the return series.

Finally, the GARCH-MIDAS component model was compared with the benchmark standard GARCH model using the DM test statistic. Thus, the result shows that compared with standard GARCH model, GARCH-MIDAS component model with macroeconomic variables can better explain the trend and risks of the coffee market. Moreover, the model helps to analyze the risk and hedging operations in the coffee market.

\subsection{Recommendations}

Based on the finding of the study researcher forwarded the following recommendations for the concerned stakeholders: 
- The government should take policy measure (like expansionary fiscal policy) to improve the overall production in the country since the value of gross domestic product has statistically significant and decreasing effect on price volatility.

- Interest rate has decreasing effect, while money supply has increasing effect on coffee price volatility. Thus, the monetary authority particularly the central bank should take appropriate monetary policy measure to stabilize the coffee market.

- Trade openness also has increasing effect on coffee price volatility. Hence, the concerned stakeholder should work to liberalize the foreign trade sector through signing interregional and international trade agreement,work on improvement the quality and diversification of its export sector.

Generally, the significance of this finding is important and is mostly attributable to the ability of the new models to incorporate different frequency macroeconomic variables directly into the specification ofhigh frequency volatility dynamicsand open a path for future researchers.However, a single model cannot be the best-suited specification for all commodity futures we consider. Hence, in the light of this empirical finding, the concerned stakeholders would have to pay a close watch on the trends of identified macroeconomic variables before making any measures related to commodity futures.

\section{Acknowledgement}

I thank my wife Mrs. Misa Getu for her endless take care of me all the time. I also thank you the National Bank of Ethiopia (NBE) and Ethiopian Commodity Exchange (ECX) market for their cooperation of data supply on time of my request.

\section{Author information}

Mr. Teshome Hailemeskel Abebe received his B.A. degree in Economics from Debre Markos Univeristy on July 2012 and M.Sc. degrees in Statistics (Econometrics) from Haramaya University on December 2017. The year after graduation, he has been serving as an instructor at Ambo University, Ethiopia.

\section{Author contribution}

Mr. Teshome Hailemeskel Abebe is the only author of this paper. He conducted the study using a Generalized Autoregressive Conditional Heteroscedasticity Mixed Interval Data Sampling (GARCH- 
MIDAS) component model which was introduced by Engel et al. (2013). The model is important to analysis high frequency data (such as daily average coffee price) volatility through decomposing conditional variance into short-term and long-term volatility component model and helps to relate different frequency macroeconomic variables (which is considered as the main source of such price volatility) to long-term volatility component. Therefore, Mr. Teshome conducted proposal development, data collection, analysis, and preparation of the manuscript well and approved it for publication.

\section{Conflict of Interest}

I confirm that there are no conflicts of interest to disclose since I am the only author of this paper with personal expenditure.

\section{Data Availability Statement}

All data generated or analyzed during this study are included in this published article (and its supplementary information files).

\section{Funding}

The author received no financial support for the research, authorship and/or publication of this article.

\section{Abbreviations}

ADF: $\quad$ Augmented Dickey Fuller

DM: $\quad$ Diebold and Mariano

ECX: $\quad$ Ethiopian Commodity Exchange

GARCH-MIDAS: Generalize Autoregressive Conditional Heteroscedascity Mixed Interval Data Sampling

GDP: $\quad$ Gross Domestic Product

MoFED: $\quad$ Ministry of Finance and Economic Development

NBE: $\quad$ National Bank of Ethiopia 


\section{REFERENCE}

Akaike, H. 1974. A New Look at the Statistical Model Identification. IEEE Transactions on Automatic Control, 19(6), 716-23.

Andersen,T. 2005. Volatility forecasting. National Bureau of Economic Research, Cambridge, UK.

Bollerslev, T. 1986. Generalized Autoregressive Conditional Heteroskedasticity. Journal of Econometrics, 31(3), 307-327.

Bollerslev, T. and Wooldridge, J. M. 1992. Quasi-Maximum Likelihood Estimation and Inference in Dynamic Models with Time-Varying Covariance. Econometric Reviews, 11(2), 143-72.

Brooks, C. 2008. Introductory Econometrics for Finance, 2nd Edition. Cambridge University Press, Cambridge, New York.

Conrad, C., \& Schienle, M. 2018. Testing for an Omitted Multiplicative Long-Term Component in GARCH Models. Journal of Business \& Economic Statistics, 0015, 1-14.

Dickey, D. A. and Fuller, W. A. 1979. Distributions of the Estimators for Autoregressive Time Series with a Unit Root. Journal of the American Statistical Association, 74: 427-431.

Diebold, F. X. and Mariano,R. S. 1995. Comparing Predictive Accuracy. Journal of Business and Economic Statistics, 13, 253-263.

Ding, Z.; Granger, C. W. J. 1996. Modeling volatility persistence of speculative returns: a new approach. Journal of Econometrics, vol. 73, no. 1, pp. 185-215.

Engle, R. and Lee,G. 1999. A long-run and short-run component model of stock return volatility. Cointegration, Causality, and Forecasting. Oxford University Press, pp. 475-497.

Engle, R. F. 1982. Autoregressive Conditional Heteroscedasticity with Estimates of the Variance of United Kingdom Inflation. Journal of Econometrics, 50, 987-1007.

Engle, R. F. and Rangel, J. G. 2008. The spline-GARCH model for low-frequency volatility and its global macroeconomic causes. Review of Financial Studies, 21(3), 1187-1222.

Engle, R. F., Ghysels, E. and Sohn, B. 2013. Stock market volatility and macroeconomic fundamentals. The Review of Economics and Statistics, 95(3), 776-797.

EU (European Commission). 2009. Historical Price volatility. Brussels, Belgium. 
Ghysels, E., Sinko, A., \& Valkanov, R. 2007. MIDAS Regressions: Further Results and New Directions. Econometric Reviews, 26, 53-90.

Ghysels, E.; Santa-Clara, P.; Valkanov, R. 2006. Predicting volatility: getting the most out of return data sampled at different frequencies. Journal of Econometrics, vol. 131, no. 1, pp. 59-96.

Harris, R., \& Sollis, R. 2003. Applied time series modeling and forecasting. England: John Wiley and Sons Ltd.

MacKinnon, J. G. 1996. Numerical distribution functions for unit root and Co-integration tests. Journal of Applied Econometrics, 11, 601-618.

Nelson, D. B. 1999. Conditional Heteroscedasticity in Asset Returns. A New Approach Econometrician, 59(2): 347-370.

Newey-West. 1987. A simple, positive semi-definite, heteroscedasticity andautocorrelation consistent covariance matrix. Econometric, 55, 703-708.

Nguyen, D. K. and Walther, T. 2018. Modeling and forecasting commodity market volatility with long-term economic and financial variables. MPRA Paper No. 84464, Munich Personal RePEc Archive. Online at:https://mpra.ub.uni-muenchen.de/84464.

Park, J. H, Nam, S. K, and Eom, K S. 2007. Market efficiency in KOSDAQ: A volatility comparison between main boards and new markets using a permanent and transitory component model. Asia-Pacific Journal of Financial Studies.

Phillips, C. B. and Perron, P. 1987. Testing for a Unit Root in Time Series Regression. Biometrics, 75, 335-346.

Poon, S. H. 2005. Forecasting volatility in financial markets: a review. Journal of Economic Literature, XLI: 478-539.

Ruobing, L., Jianhui, Y. and Chuan, Y. R. 2019. The Impact of Macroeconomic News onChinese Futures. International Journal of Financial Studies, 7, 63; doi:10.3390/ijfs7040063.

Wang, F. and Ghysels, E. 2014. Econometric Analysis of Volatility Component Models. Econometric Theory, 31(02), 362-393.

Zakoian, J. M. 1994. Threshold Hetroskedastic Models. Journal of Economic Dynamics and Control, 18, 931-944. 
Figures

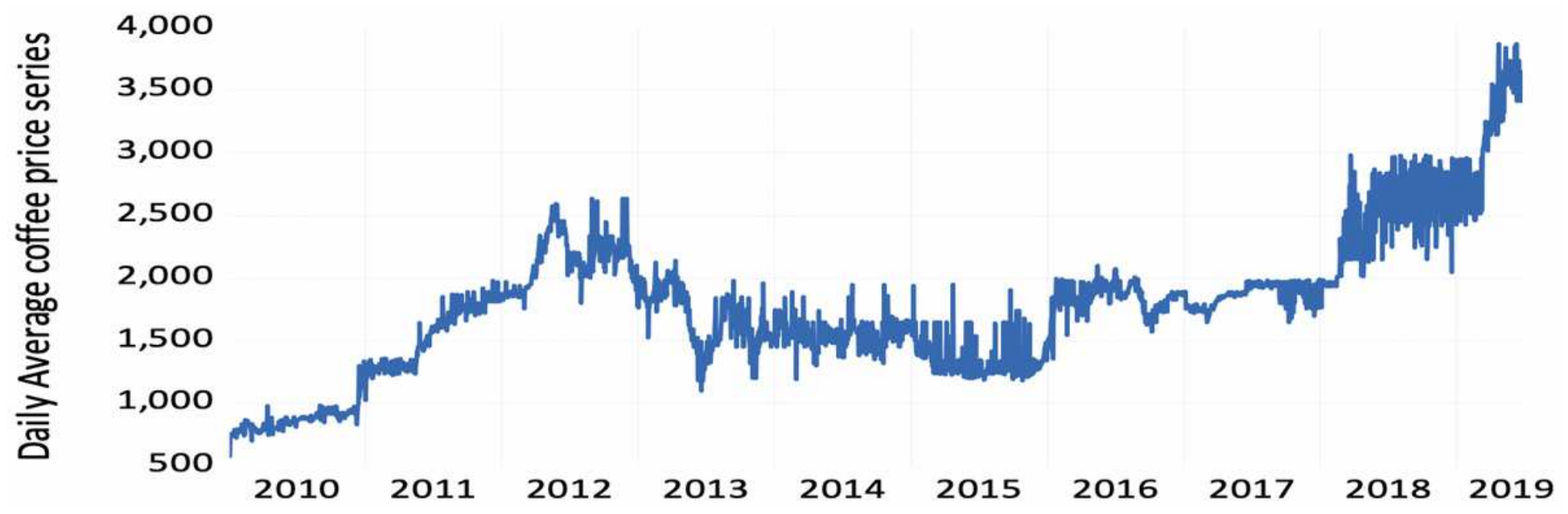

Figure 1

Average daily coffee price series from January 1, 2010 to June 30, 2019

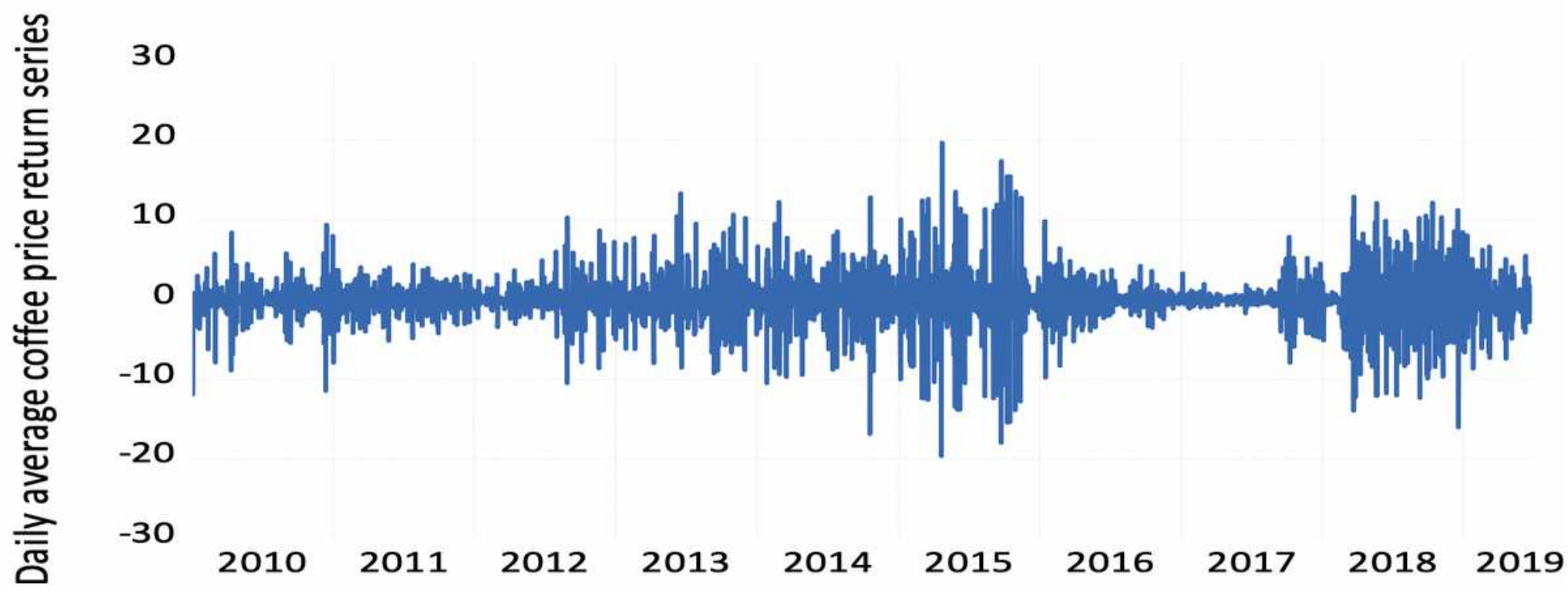

Figure 2

Average Daily coffee Return series from January 01, 2010 to June 30, 2019 
100

Money supply

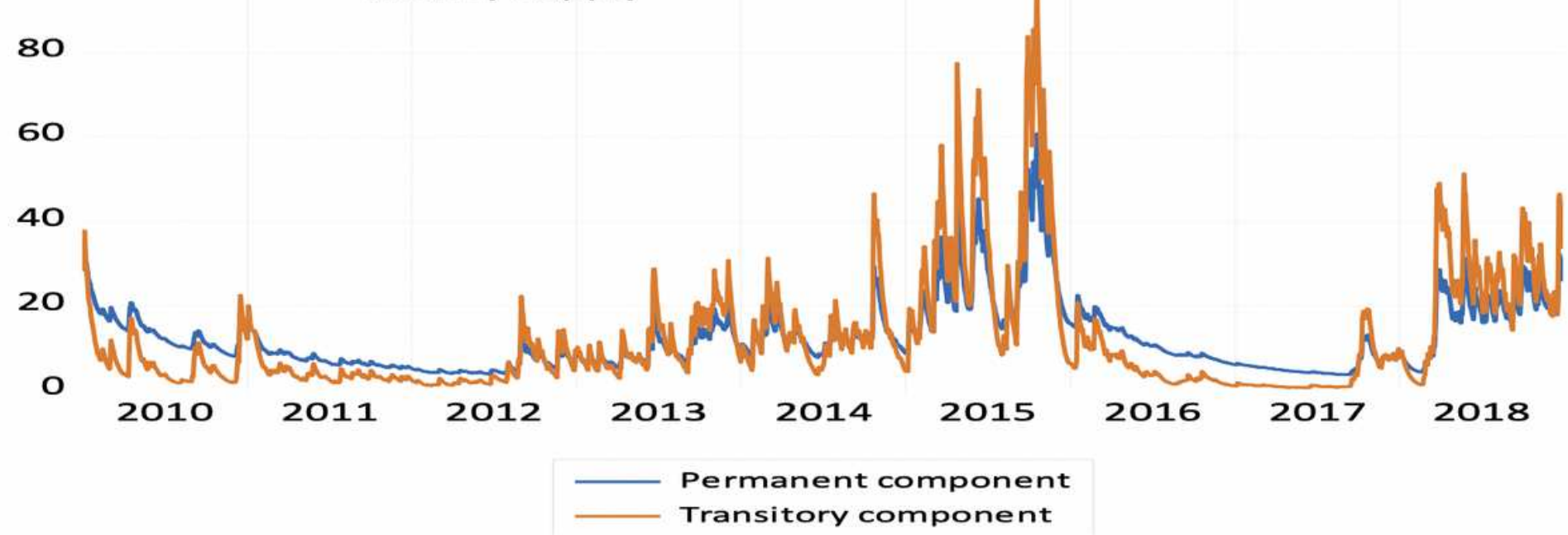

Figure 3

Shows the daily long-term (blue line) and short-term (red line) volatility components as estimated by the GARCH-MIDAS models with money supply as explanatory variables.

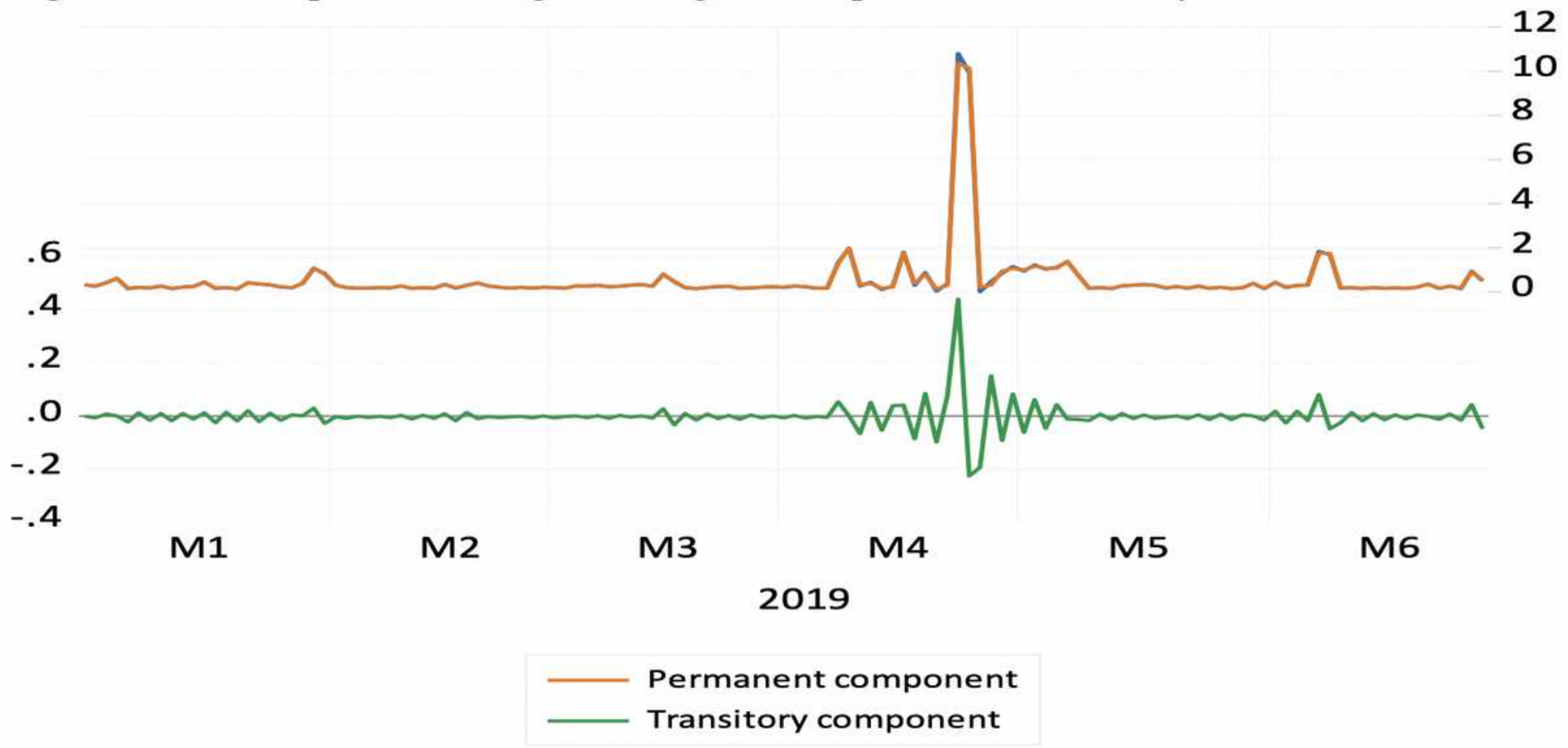

Figure 4

Out-sample forecasting of average coffee price return volatility 